\title{
Long-term features of tropical cyclones affecting Taiwan
}

\author{
Yueh-Shyuan $\mathrm{Wu}^{1}$, Hsu-Feng Teng ${ }^{1,2}$, Johnny C. L. Chan ${ }^{3}$, and Cheng-Shang Lee ${ }^{1, *}$ \\ ${ }^{1}$ Department of Atmospheric Sciences, National Taiwan University, Taipei City, Taiwan \\ ${ }^{2}$ National Center for Atmospheric Research, Boulder, Colorado, USA \\ ${ }^{3}$ School of Energy and Environment, City University of Hong Kong, Hong Kong, China
}

Article history:

Received 5 September 2018

Revised 21 March 2019

Accepted 25 April 2019

Keywords:

Wavelet analysis, Tropical cyclone affecting Taiwan, Interannual scale, Interdecadal scale, Tropical cyclone activity

\section{Citation:}

Wu, Y.-S., H.-F. Teng, J. C. L. Chan, and C.-S. Lee, 2019:

Long-term features of tropical cyclones affecting Taiwan. Terr. Atmos. Ocean. Sci., 30, 793-802, doi: 10.3319/TAO.2019.04.25.01

\begin{abstract}
This study investigates the long-term variations of tropical cyclones (TCs) that affected Taiwan during 1970 - 2014 using wavelet analysis of TC activity, and identifies the corresponding large-scale environments related to such variations. Two significant oscillations in the numbers of TCs that affect Taiwan are found: interannual (3-5-year) and interdecadal (10-16-year). The distribution of TC formation locations and the corresponding large-scale environments associated with the positive and negative phases of the interannual and interdecadal oscillations are examined. In years when both the interannual and interdecadal oscillations are positive, the lowlevel relative vorticity around Taiwan is above normal, which therefore provides a more favorable environment for TC formation in the region near Taiwan. At the same time, the large-scale environment provides a steering flow over the above-normal formation region to steer the TCs towards Taiwan. In the negative phases, anomalies of low-level relative vorticity near Taiwan become negative so that TC formation is not favored. The steering flows over areas of favorable TC formation locations also do not tend to steer the TCs to move toward Taiwan. Thus, the positive and negative phases of the interannual and interdecadal variations of the number of TCs that affect Taiwan can be explained by those in the TC formation locations and the large-scale steering flow. However, none of these variations appears to be related to the El NiñoSouthern Oscillation.
\end{abstract}

\section{INTRODUCTION}

Tropical cyclone (TC) is the most significant severe weather system in the western North Pacific (WNP), including Taiwan. Moreover, it is one of the most critical issues in the natural disasters in Taiwan. On the average, 3 - 4 typhoons affect Taiwan and bring $27.6 \%(600-800 \mathrm{~mm})$ of the total annual rainfall to Taiwan (Lee et al. 2012). Therefore, identifying the environmental features associated with TCs affecting Taiwan (ATTCs, to be defined in section 2.2) is essential for the prevention work related to typhoon disasters.

Many previous studies have examined the TC activity (including TC formations, numbers, and tracks) on different time scales in the WNP: interdecadal (Ho et al. 2004; Kim et al. 2005; Liu and Chan 2008, 2013), interannual (Wang and Chan 2002; Wu et al. 2004; Wang and Wu 2016), and intraseasonal (Kim et al. 2008; Hong et al. 2010). These studies

\footnotetext{
* Corresponding author

E-mail: cslee@ntu.edu.tw
}

have revealed that although a TC is a synoptic-scale system, its track and formation location are controlled by the large-scale environments or long-term oscillations, which may change the sea surface temperature, the flow patterns, the position of the monsoon trough, the tropical upper tropospheric trough, the location of the subtropical high, and the structure of the vertical wind shear. Therefore, to understand the controlling factors for the different temporal variations of ATTCs, the TC tracks, formation locations, and the corresponding environments need to be studied.

$\mathrm{Wu}$ et al. (2004) examined the relationship between the El Niño-Southern Oscillation (ENSO) and TC activity in the western part of the WNP. They showed that fewer TCs occurred near the land area in the late season of El Niño years, while more TCs were found near the east coast of China in the late season of La Niña years. This feature is attributed to the shift of TC formation location and the change of the strength of the 500-hPa subtropical high. Camargo 
et al. (2007a, b) used cluster analysis to classify different track patterns, and compared the TC formation locations, distribution of landfall, and accompanying environmental circulation between different patterns of TC track. They also indicated that TC activity is affected by ENSO through changes in flow patterns and TC formation locations in different ENSO phases. Harr and Elsberry $(1991,1995)$ also used cluster analysis to show that the interannual variation of the subtropical high and the monsoon trough caused by ENSO would change the TC track patterns in the WNP.

On a decadal time scale, Liu and Chan (2008) used an Empirical Orthogonal Function analysis to identify the three main patterns of TC track and their corresponding largescale circulations in the WNP, and found that two of them are correlated with the Pacific Decadal Oscillation (PDO). Liu and Chan (2013) further discussed the interdecadal variation of TC numbers in the WNP, and showed that the reduction in TC numbers in the inactive phases can be attributed to the strengthening of the subtropical high and the interdecadal variation of the vertical wind shear.

Hong et al. (2010) focused on Typhoon Morakot (2009) and analyzed multiple time scale effects using a wavelet analysis. Their results showed that typhoon Morakot (2009) was influenced by a 10-30-day and a 30-60-day period oscillation when it affected Taiwan, which caused moisture to be transported northward and subsequently contributed to the extremely heavy rainfall in southern Taiwan before the typhoon Morakot (2009) made landfall at Taiwan. Similarly, Wu et al. (2011) also found that the track and motion speed of Typhoon Morakot (2009) were affected by two low-frequency (quasi-biweekly and intraseasonal) oscillations during the period when Morakot (2009) was approaching Taiwan.

Most previous studies focused on the TC rainfall on weather or climate scales over the entire WNP or mainland China. Very few have investigated TCs that affect Taiwan or near Taiwan and the large-scale environments associated with these TCs in the long-term or multi-time scales. The purpose of this study is therefore to identify the significant variations of ATTCs and their corresponding large-scale environments. The data and methodology used are described in section 2. The wavelet analysis results of ATTCs and environmental composites are presented in section 3. The discussion and conclusion are given in section 4 .

\section{METHODOLOGY}

\subsection{Data}

The 6-hourly TC tracks are obtained from the Joint Typhoon Warning Center. The formation of a TC is defined as a disturbance with a maximum wind speed greater than 25 knots. Because the first meteorological satellite was launched around 1960 and the scanning radiometers were used after 1970 (Velden et al. 2006), this study only ana- lyzes ATTCs after 1970 to reduce the uncertainties in identifying TC formation locations and tracks over the ocean. The Reanalysis-1 from the US National Centers for Environmental Prediction, which is a 6-hourly dataset (Kalnay et al. 1996) for the period $1970-2014$ with $2.5^{\circ} \times 2.5^{\circ}$ horizontal resolution and 17 vertical levels, is used to examine the environmental parameters associated with ATTCs. The Oceanic Niño Index (ONI) and definitions of El Niño, La Niña, and normal years are obtained from the Climate Prediction Center of National Oceanic and Atmospheric Administration to represent the ENSO signal and to calculate the difference in ATTCs between different ENSO phases. The PDO index is obtained from the Tokyo Climate Center of Japan Meteorological Agency.

\subsection{Definition of ATTCs}

A TC that passes over the targeted area $118-125^{\circ} \mathrm{E}$, $20-27^{\circ} \mathrm{N}$ (red box in Fig. 1a) is defined as an ATTC in this study. This targeted area is chosen by considering the TC track passage density around Taiwan (shaded in Fig. 1a) and to cover most of the TC track distribution. The track passage density considers the accumulated number of 6-hourly TC tracks in each $4^{\circ}$ latitude $\times 4^{\circ}$ longitude box. A total of 260 ATTCs can be identified during 1970 - 2014, and the time series of yearly ATTC number is shown in Fig. 1b. Variations in yearly ATTC number of different time scales are revealed in Fig. 1b, such as annual, decadal, and long-term trend. The distribution of ATTC passage frequency in this targeted area is similar to the distribution of the passage frequency of typhoons affecting Taiwan defined by the Central Weather Bureau. Note that the operational definition considers only the disturbances that reach tropical storm intensity (maximum wind speed $\geq 34$ knots) and uses some subjective criteria (e.g., relative time and distance to the specific location). In this study, however, a fixed domain $\left(118-125^{\circ} \mathrm{E}, 20-27^{\circ} \mathrm{N}\right)$ and the TC intensity are considered to define the ATTCs objectively.

\subsection{Wavelet Analysis}

Following the methods used in Teng (2016), a wavelet analysis (Morlet 1983; Torrence and Compo 1998) is applied to the ATTC numbers during 1970 - 2014. In this study, the 1-D continuous wavelet transform with the Morse wavelet (Olhede and Walden 2002) as the mother wavelet is used. The 45-year ATTC data are normalized first and then transformed into wavelet amplitude, which presents the amplitudes for each year and for each period. To examine the statistical significance of wavelet analysis, the Monte Carlo simulation test at a 95\% confidence level is used. The significant amplitude of wavelet analysis indicates the major variation signals of ATTC for different time scales and the decomposed components for different years. 

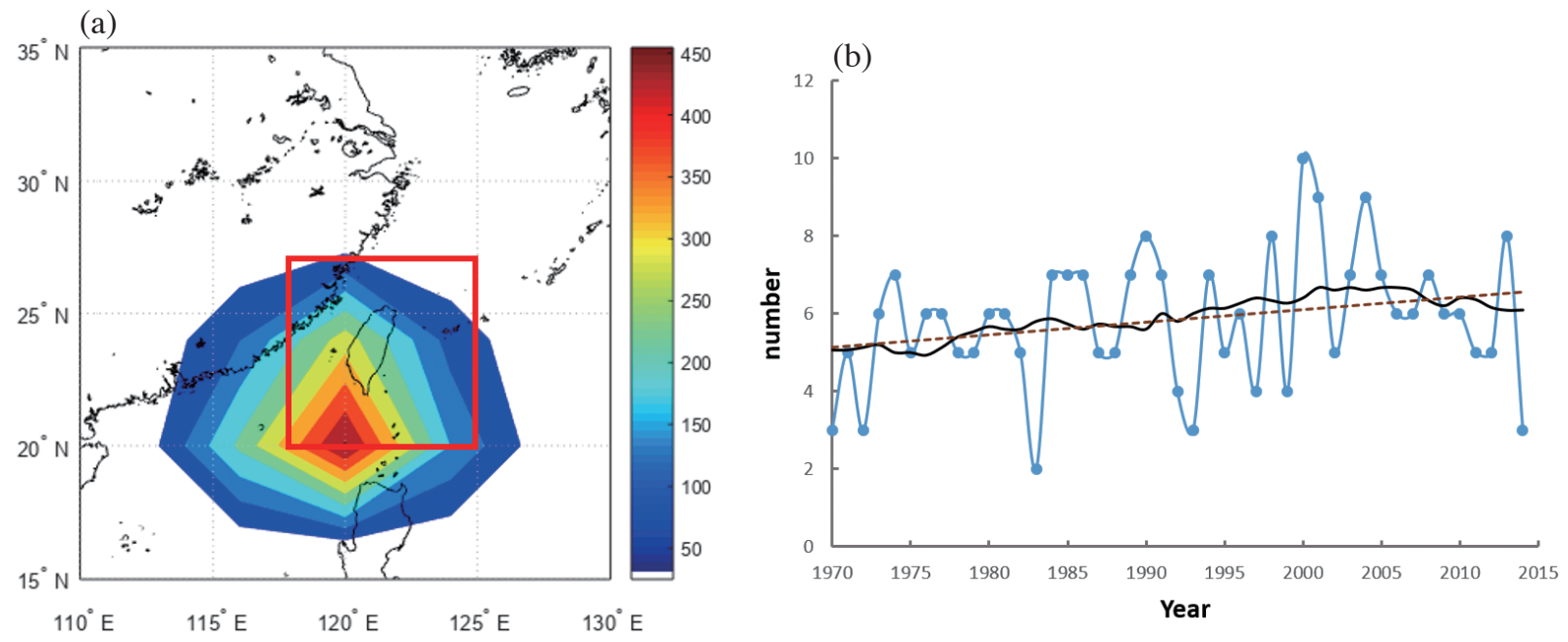

Fig. 1. (a) The gridded ATTC passage density (number in the $4^{\circ} \times 4^{\circ}$ box) during $1970-2014$ (shaded) and the targeted area (red box) of the ATTC definition. (b) The time series of ATTC number from 1970 - 2014. Black line shows the 15-year running mean and brown dashed line shows the linear trend.

\section{RESULTS}

\subsection{Major Periods of ATTC Number}

The wavelet analysis (Fig. 2) shows two significant periods in the ATTC number during 1970 - 2014: 3-5-year (interannual) and 10-16-year (interdecadal). Most significant amplitudes occur over the period 1982 - 1994 on the interannual scale and over the period 1987 - 2006 on the interdecadal scale. Note that the period of significant amplitudes on the interdecadal scale increases gradually from $9-12$ years to $11-17$ years. This feature is revealed in the longterm increasing trend of ATTC number in the past 45 years $(R=0.25$, which is not statistically significant; Fig. 1b).

The time series of the wavelet amplitudes of the interannual (3-5-year) and interdecadal (10-16-year) signals are reconstructed (Fig. 3). The amplitude of the reconstructed time series for interannual signal (Fig. 3a) is similar to the significant amplitude of the wavelet result (Fig. 2). For the interdecadal signal, there are three full cycles for 10-year signal and two full cycles for 15-year signal in the effective wavelet period, and these cycles can superpose or compensate each other. The phases of each scale from $10-16$ years are consistent after 1993, thus the amplitude of reconstructed interdecadal signal is greater for the period of 1993 - 2014 than for the period of 1970 - 1992.

To examine the variations further, the years with reconstructed amplitudes exceeding one standard deviation within each time scale are identified as the representative years of positive or negative phase for the interannual and the interdecadal periods, respectively (Table 1 ). Based on the Student's $t$ test, except for the negative phase of interdecadal scale, the numbers of ATTCs are higher and statistically significant than the average in the positive phases and lower in the negative phases. Furthermore, the difference in the number of ATTCs between the positive and negative phases is statistically significant at the $99 \%$ level on the interannual scale and close to $90 \%$ on the interdecadal scale.

Analyzing the annual TC track passage density (based on a $4^{\circ} \times 4^{\circ}$ box) for positive and negative phases in the two scales (Fig. 4) shows that TC track passages distribute more around Taiwan and the Philippines, and some along the recurving track to Japan in the positive phases on the interannual (Fig. 4a) and interdecadal scales (Fig. 4c). Although both positive phases for these two time scales have more TC activities near Taiwan, TC track passage density in the South China Sea is much higher for the interannual scale than for the interdecadal scale. On the other hand, in the negative phases for these two time scales, the regions of maximum TC track passages are located more southward (Figs. 4b and d) than those in the positive phases. Comparing TC track passage density in the negative phases between interannual and interdecadal scales indicates that higher TC track passage density is observed at the south of $15^{\circ} \mathrm{N}$ and more TCs occur around the Philippines in the interannual scale (Fig. 4b), while higher TC track passage density exists at the north of $15^{\circ} \mathrm{N}$ and more TCs recurve northward in the interdecadal scale (Fig. 4d).

To analyze the anomalies of TC track passage density, the TC track passage density is normalized to the passage frequency, which is defined as the number of TC track passage of each grid divided by that of whole targeted domain in each phase. The same calculation is also applied to TC formation frequency. Figure 5 shows positive anomalies of TC track passage frequency near Taiwan in both positive phases on the interannual (Fig. 5a) and interdecadal (Fig. 5c) scales, suggesting that more TCs pass by Taiwan in these selected years. In addition, in the positive phase on the interannual scale, there is higher frequency for TCs 


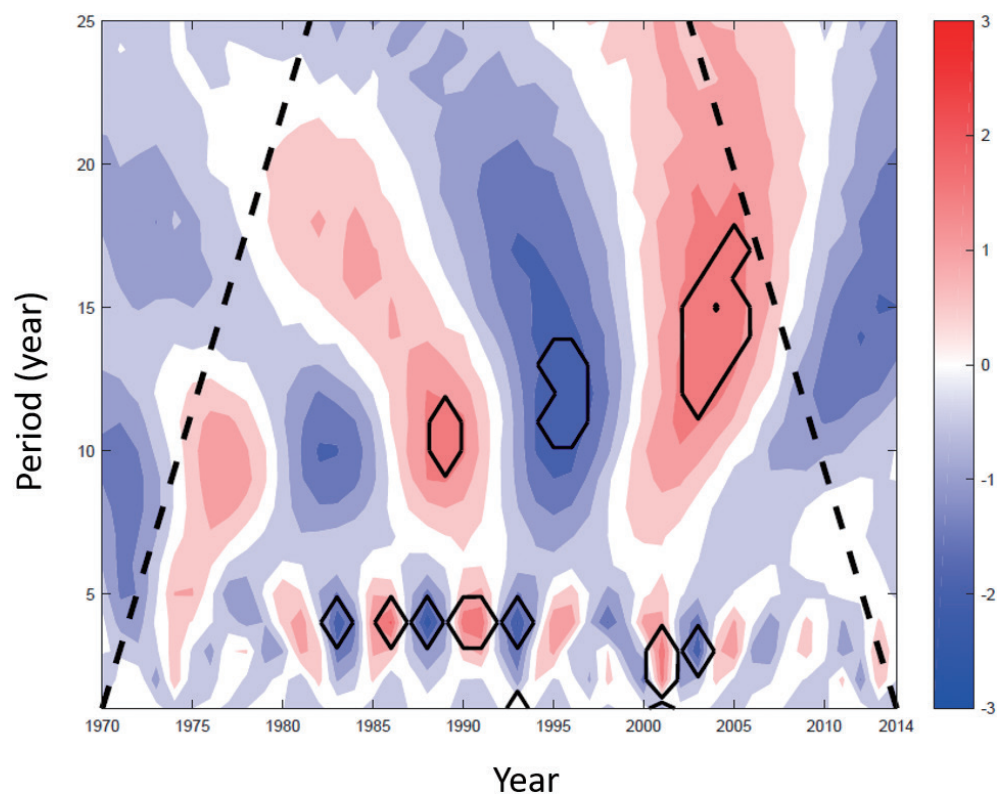

Fig. 2. Power spectrum of ATTC number during 1970 - 2014 derived from the wavelet analysis. Color shaded indicates the amplitude of wavelet signal. Dashed lines show the effective boundary of wavelet period. Black contours show the significant signals which pass the Monte Carlo simulation test at a $95 \%$ confidence level.
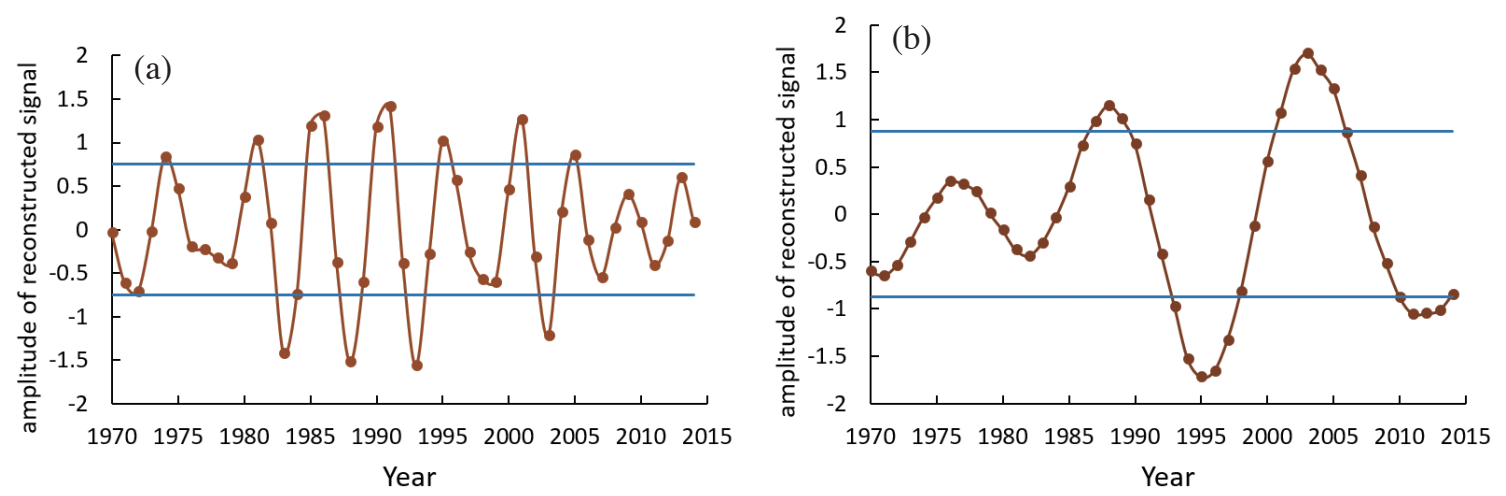

Fig. 3. Time series of the reconstructed amplitudes from wavelet analysis of the ATTC number during 1970 - 2014. (a) interannual (3-5-year), and (b) interdecadal (10-16-year). Blue lines show the values of one standard deviation of the amplitudes in that time scale.

Table 1. Years of the positive and negative phases in the interannual and interdecadal scales, averages of ATTC number, and the $\mathrm{p}$-values of Student's $t$ test. $\mathrm{P}$-value ${ }^{1}$ indicates the $\mathrm{p}$-value for the difference between the positive and negative phases, and $\mathrm{p}$-value ${ }^{2}$ indicates the $\mathrm{p}$-value for the difference between each phase of each scale and the climatology during 1970 - 2014.

\begin{tabular}{cccccc}
\hline & & Year & ATTC & p-value & p-value \\
\hline \multirow{2}{*}{ Interannual } & Positive phase & $1974,1981,1985,1986,1990,1991,1995,2001,2005$ & 7.0 & & 0.03 \\
& Negative phase & $1983,1988,1993,2003$ & 4.3 & 0.01 & 0.04 \\
\hline \multirow{2}{*}{ Interdecadal } & Positive phase & $1987,1988,1989,2001,2002,2003,2004,2005$ & 6.8 & \multirow{2}{*}{0.11} & 0.09 \\
& Negative phase & $1993,1994,1995,1996,1997,1998,2011,2012,2013$ & 5.7 & & 0.39 \\
\hline \multirow{2}{*}{ Total } & & $1970-2014$ & 5.8 & & \\
\hline
\end{tabular}


(a) positive, interannual

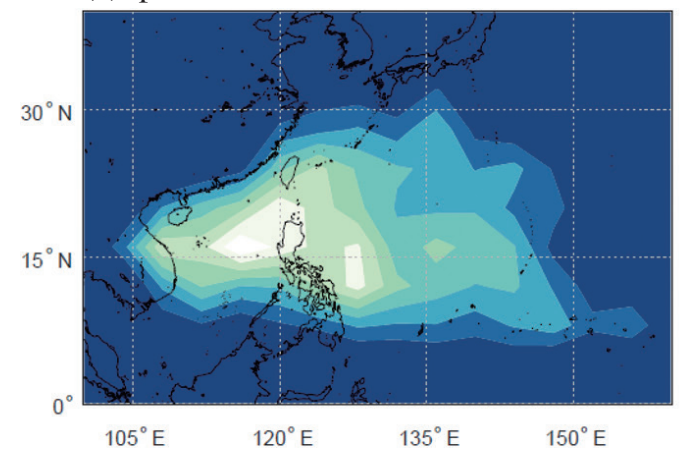

(c) positive, interdecadal

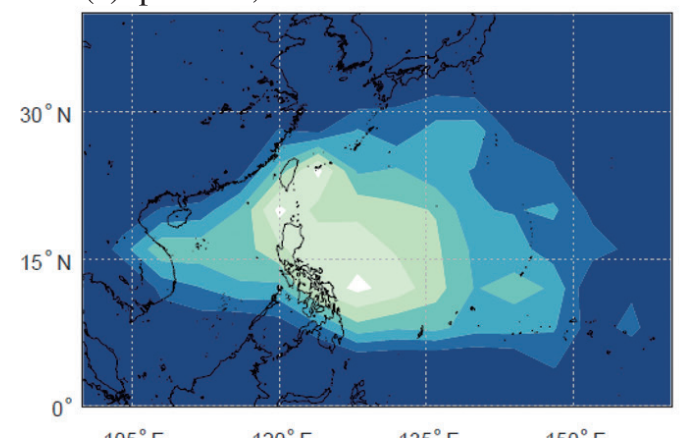

(b) negative, interannual

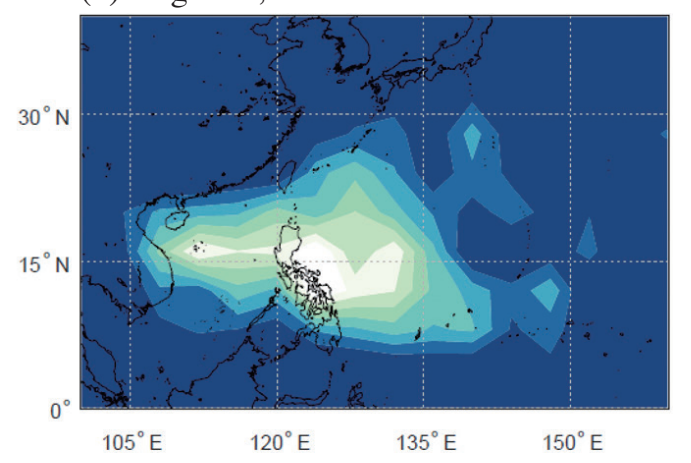

(d) negative, interdecadal

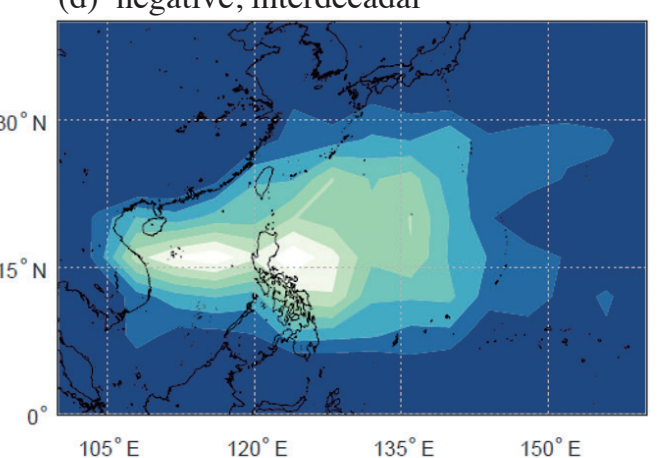

Fig. 4. The distribution of annual TC track passage density (number per year in $4^{\circ} \times 4^{\circ}$ box). (a) and (c) positive phases, and (b) and (d) negative phase; (a) and (b) are for the interannual scale, and (c) and (d) for the interdecadal scale.

(a) positive, interannual

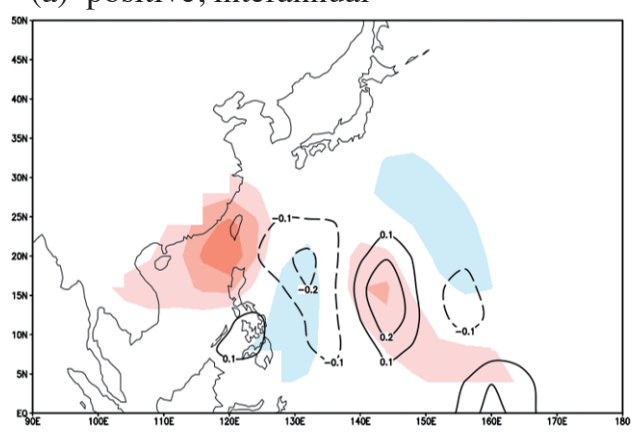

(c) positive, interdecadal

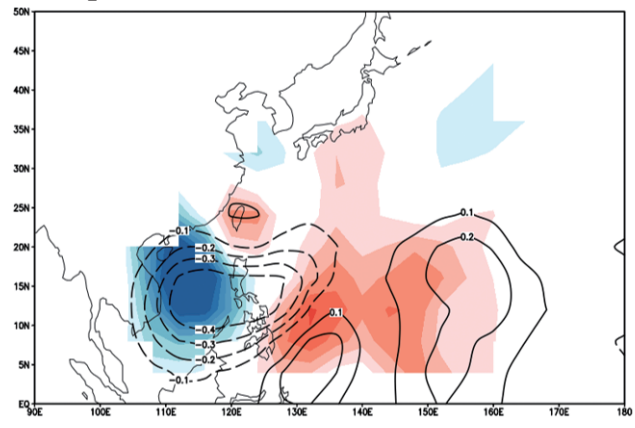

(b) negative, interannual

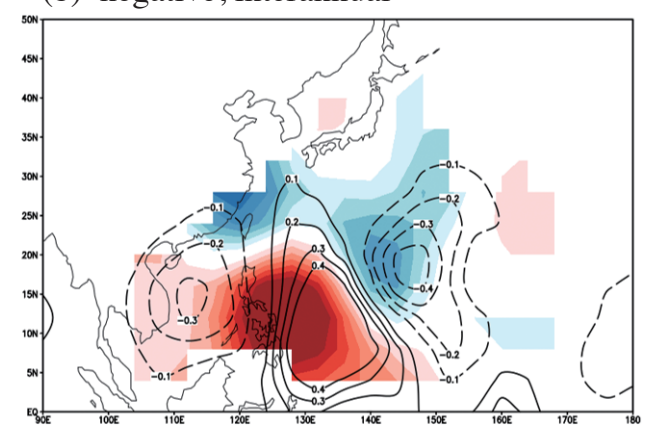

(d) negative, interdecadal

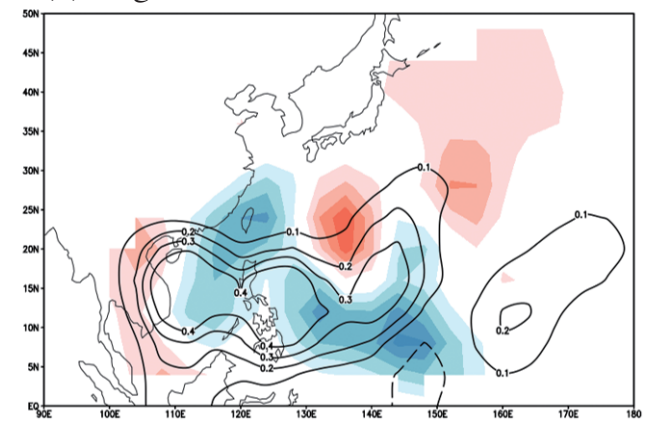

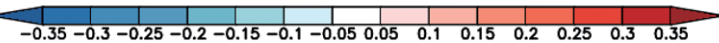

Fig. 5. As in Fig. 4 except for the distribution of TC track passage frequency anomaly (shaded, \%, which passes the $t$ test at a $90 \%$ confidence level) and TC formation frequency anomaly (contour, \%) from the climatology (1970 - 2014). 
formed in the area of $140-150^{\circ} \mathrm{E}, 5-20^{\circ} \mathrm{N}$, where positive anomalies of TC track passage frequency are found. In the positive phase on the interdecadal scale, higher frequencies for TC formation are observed in the areas of $145-160^{\circ} \mathrm{E}$, $5-20^{\circ} \mathrm{N}$ and $125-135^{\circ} \mathrm{E}, 0-10^{\circ} \mathrm{N}$, and the positive anomalies of TC track passage frequency are mainly distributed around these areas.

In the negative phases, negative anomalies of TC track passage frequency near Taiwan are found on the interannual scale (Fig. 5b) with higher frequency for TCs formed around $135^{\circ} \mathrm{E}$ but the anomalies of TC track passage frequency show that fewer TCs passing by Taiwan but more over the Philippines. On the interdecadal scale (Fig. 5d), more TCs form around the area from the South China Sea to $150^{\circ} \mathrm{E}$ but TCs have lower frequencies passing by Taiwan and the Philippines. Note that the major areas with higher frequencies of TC formation and track passage are not overlapping, because TCs tend to make the landfall at Indochina or recurve northward to Japan in this phase.

\subsection{Corresponding Environmental Conditions}

Based on the results of wavelet analysis, composites of relative vorticity and circulation in the representative years are made to examine the difference between the positive and negative phases on the interannual and interdecadal scales. Previous studies have shown that the low-level relative vorticity and the mid- to low-level circulation are the most important factors to influence TC formation and TC motion in the WNP, respectively (Lee 1989; Harr and Elsberry 1991, 1995; Fu et al. 2012; Teng 2016). Thus, they are analyzed in this study to examine the TC activity. Considering the seasonal variations of parameters, the composites are only done for the period from July to October, which is the main TC season in the WNP and $83 \%$ of ATTCs occur in this period. The climatology of each parameter is the average during the period July - October, 1970 - 2014. For the interannual scale, the composites of 850 -hPa relative vorticity anomalies show that positive anomalies of TC formation (Fig. 5a) are associated with the positive anomalies of $850-\mathrm{hPa}$ relative vorticity in the positive phase (Fig. 6a). Positive vorticity anomalies are found around the Philippines, the area of 135 $-150^{\circ} \mathrm{E}, 10-20^{\circ} \mathrm{N}$, and the area of $110-120^{\circ} \mathrm{E}, 10-20^{\circ} \mathrm{N}$. Moreover, cyclonic circulations in the anomalies of 500$\mathrm{hPa}$ wind field (Fig. 7a) are found in the same regions. The mid-level flow therefore will steer the TCs formed around the Philippines and in the area of $135-150^{\circ} \mathrm{E}, 10-20^{\circ} \mathrm{N}$ to move toward Taiwan, resulting in the positive anomalies of ATTC number. On the other hand, in the negative phase (Fig. 6b), there are positive anomalies of 850-hPa vorticity around the areas of $120-140^{\circ} \mathrm{E}, 5-12^{\circ} \mathrm{N}$ and $150-160^{\circ} \mathrm{E}$, $0-10^{\circ} \mathrm{N}$, which are associated with the positive anomalies of TC formation (Fig. 5b) at lower latitudes, except for the area of $130-140^{\circ} \mathrm{E}, 15-20^{\circ} \mathrm{N}$ where the TC formation anomaly is positive and the vorticity anomaly is negative. Note that besides the low-level vorticity, there are other parameters that can affect TC formation (Gray 1998; Emanuel and Nolan 2004; Camargo et al. 2007b; Fu et al. 2012). The mid-level flows show an anticyclonic circulation (Fig. 7b) around the area of $110-155^{\circ} \mathrm{E}, 12-30^{\circ} \mathrm{N}$. Therefore, TCs formed in the negative years on the interannual scale tend to move westward at lower latitudes towards the Philippines, causing a significant decrease in the ATTC number.

For the interdecadal scale, positive anomalies of 850hPa vorticity (Fig. 6c) are found around the areas of 150 $160^{\circ} \mathrm{E}, 0-15^{\circ} \mathrm{N}$ and $125-145^{\circ} \mathrm{E}, 10-23^{\circ} \mathrm{N}$ in the positive phase, thus the TCs tend to form in these two areas which also match roughly part of the distribution of TC formation frequency anomalies (Fig. 5c). Anomalies of 500-hPa wind field (Fig. 7c) show that easterlies and cyclonic circulations around these areas are favorable for TCs to move to the east of the Philippines, Taiwan, and Japan. In the negative phase (Fig. 6d), negative anomalies of 850-hPa vorticity exist at areas around the Philippines, Taiwan, and Japan, and positive anomalies which match part of the positive anomalies of TC formation frequency (Fig. 5d) distribute around the area of $130-142^{\circ} \mathrm{E}, 18-28^{\circ} \mathrm{N}$. However, the anomalies of 500-hPa wind field (Fig. 7d) show that there are westerlies around Taiwan and an anticyclonic circulation to the east of the Philippines, mostly covering the area with negative anomalies of TC track distribution. Therefore, TCs tend to recurve and move toward the northeast or form near Indochina, causing the ATTC number to decrease while the number of TCs that move to the east of Japan or make landfall at Indochina increases (Fig. 5d).

\section{DISCUSSION AND CONCLUSION}

In the WNP, the TC activities are influenced by different large-scale events and different time scales, e.g., Madden-Julian Oscillation, ENSO, and PDO. However, there is no study that analyzes the TC activities around Taiwan on various time scales in the past. To improve the understanding of multi-scale impacts of TCs on Taiwan, the features of ATTC (or TC affecting Taiwan) in different time scales must be investigated.

In this study, for the first time, a 3-5-year and a 10-16year scales of ATTC variations in 1970 - 2014 are found using wavelet analysis. Note that although the 3-5-year period is similar to the ENSO period (Julian and Chervin 1978; Trenberth 1997) and some of the representative years in the positive (negative) phase are consistent with the El Niño years (La Niña years), the correlations between the ATTC variations for interannual scale and the ENSO signals of the Eastern and Central Pacific type are not significant, according to the Pearson's correlation test $(\mathrm{R}=0.03$ and 0.03$)$. This result indicates that the ENSO modulations do not impact significantly on TC activity around Taiwan but affect 
(a) positive, interannual

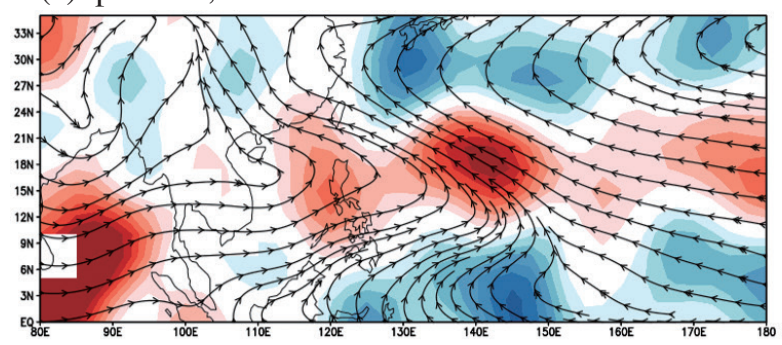

(c) positive, interdecadal

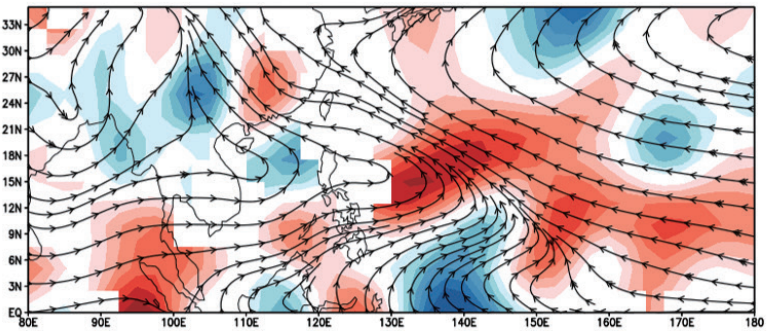

(b) negative, interannual

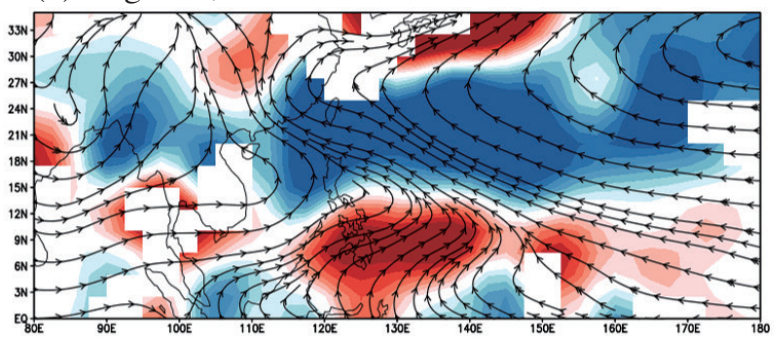

(d) negative, interdecadal

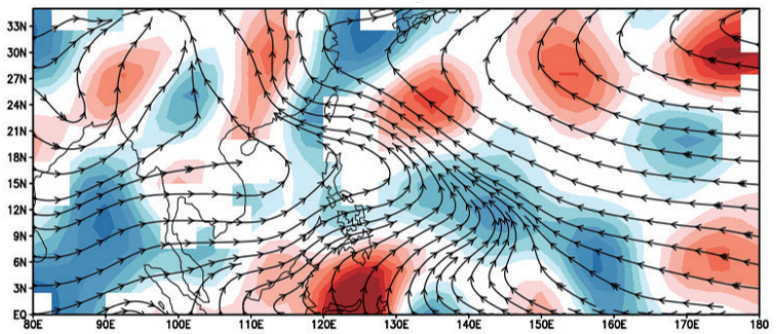

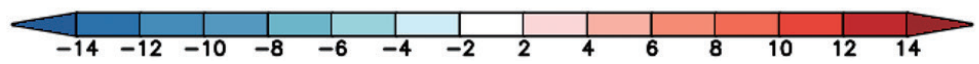

Fig. 6. As in Fig. 4 except for the 850-hPa wind field (stream line) and the anomalies of relative vorticity (shaded, $10^{-5} \mathrm{~s}^{-1}$, which passes the $t$ test at a $90 \%$ confidence level) from the climatology (1970 - 2014).

(a) positive, interannual

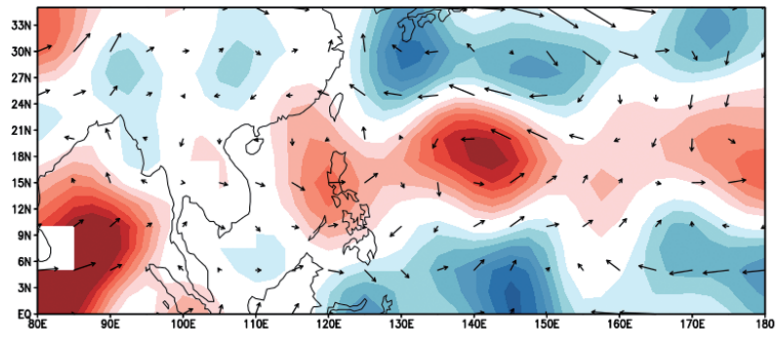

(c) positive, interdecadal

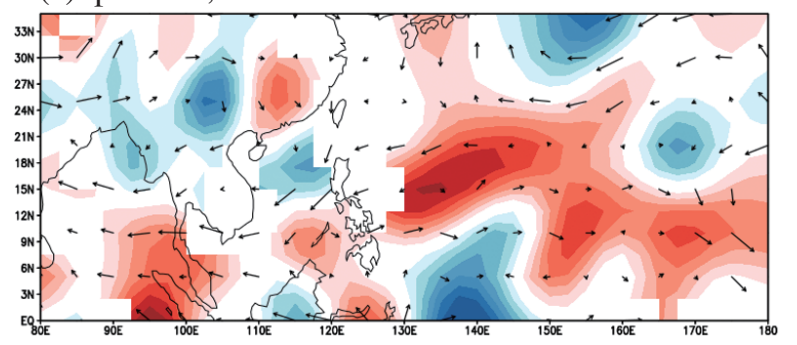

(b) negative, interannual

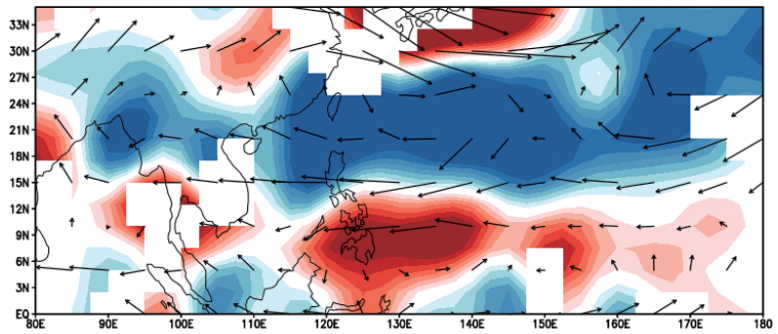

(d) negative, interdecadal

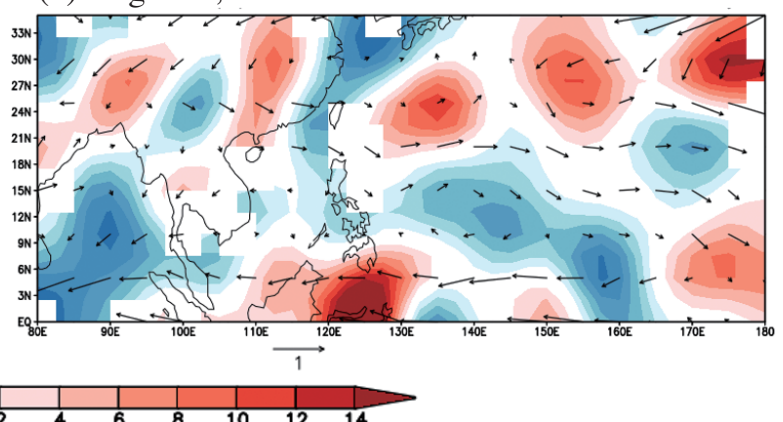

Fig. 7. As in Fig. 4 except for the anomalies of 500-hPa wind field (vector, $\mathrm{m} \mathrm{s}^{-1}$ ) and $850-\mathrm{hPa}$ relative vorticity $\left(\right.$ shaded, $10^{-5} \mathrm{~s}^{-1}$, which passes the $t$ test at a $90 \%$ confidence level) from the climatology (1970 - 2014). 
the TC activity in the entire WNP (Chan 2000; Teng et al. 2014).

Previous studies have verified that the TC activity in the entire WNP has the interdecadal variations, which are attributed to the decadal variations of large-scale sea surface temperature, low-level vorticity, and vertical wind shear in the WNP (Chan 2008; Liu and Chan 2008, 2013; Zhao and Wang 2016). However, the interdecadal variations of ATTC number are not consistent with the variations of TC activity in the entire WNP found in these previous studies (Chan 2008; Liu and Chan 2008, 2013; Zhao and Wang 2016) and are also not correlated with PDO index $(\mathrm{R}=0.04)$. Moreover, some composite features for the positive and negative phases are similar to those of ENSO events, but the ATTC variations for interdecadal scale are not significantly correlated with the ENSO signals of the Eastern and Central Pacific type (defined by $\mathrm{Yu}$ et al. 2012), according to the Pearson's correlation test $(\mathrm{R}=0.09$ and 0.06$)$.

The patterns of TC track and formation location are influenced by the large-scale circulation over the WNP (Harr and Elsberry 1991, 1995). In this study, the patterns of TC track and formation location and their corresponding synoptic environments differ obviously between the positive and negative phases for the interannual and interdecadal scales. In conclusion, TCs tend to form in the areas that have positive anomalies of low-level vorticity, and those areas are mostly located near Taiwan in the positive phases. Besides, the steering flows are also favorable to TCs moving toward or pass by the area around Taiwan. Thus, the TC activity near Taiwan increases in the positive phases. The opposite situation occurs in the negative phases.

Similar environmental features to Liu and Chan (2008) are found in this study. In the eastern Asia and western WNP, more TCs occur at the area where the anomalies of cyclonic flows, easterlies, or southerlies exist at the middle levels. In contrast, less TCs occur at the area where the anomalies of anticyclonic flows, westerlies, or northerlies exist at the middle levels, leading to TCs tending to recurve or move west-northwestward.

The results of this study indicate that although the area around Taiwan is part of the WNP, the feature of ATTC activity significantly differs from that of the entire WNP. Even the influence of interannual and interdecadal oscillation (e.g., ENSO and PDO) on TC activity over the WNP has been studied, the two significant periods of ATTC found in this study are not related to any known large-scale oscillation. Besides, although the interdecadal scale plays a critical role on the increased long-term trend in ATTC number, the features of global warming might also contribute to this trend (Tu et al. 2009). However, because there is no significant global warming period in the results of wavelet analysis for ATTC, the features that global warming might affect ATTC number through the interactions across different time scales, cannot be clearly addressed in the current study. In summary, the variation of ATTC activity is unique, which may be attributed to the special location of Taiwan and the interactions among the multi-scale impacts at the region around Taiwan. These features and mechanisms need and deserve to be further studied in the future.

Acknowledgements The work of Johnny C. L. Chan, who is supported by City University of Hong Kong, was carried out during his visit to the National Taiwan University. Cheng-Shang Lee, Yueh-Shyuan $\mathrm{Wu}$, and Hsu-Feng Teng are supported by the National Taiwan University. Hsu-Feng Teng is also supported by the National Center for Atmospheric Research. This research is supported by the Ministry of Science and Technology (MOST) of the Republic of China (Taiwan) under Grants MOST 106-2111-M-002-009-, 107-2111-M-002-012-, and 107-2625-M-002-008-

\section{REFERENCES}

Camargo, S. J., A. W. Robertson, S. J. Gaffney, P. Smyth, and M. Ghil, 2007a: Cluster analysis of typhoon tracks. Part I: General properties. J. Climate, 20, 3635-3653, doi: 10.1175/JCLI4188.1. [Link]

Camargo, S. J., A. W. Robertson, S. J. Gaffney, P. Smyth, and M. Ghil, 2007b: Cluster analysis of typhoon tracks. Part II: Large-scale circulation and ENSO. J. Climate, 20, 3654-3676, doi: 10.1175/JCLI4203.1. [Link]

Chan, J. C. L., 2000: Tropical cyclone activity over the western North Pacific associated with El Niño and La Niña events. J. Climate, 13, 2960-2972, doi: 10.1175/1520-0442(2000)013<2960:TCAOTW>2.0. $\mathrm{CO} ; 2$. [Link]

Chan, J. C. L., 2008: Decadal variations of intense typhoon occurrence in the western North Pacific. Proc. R. Soc London Ser. A-Math. Phys. Eng. Sci., 464, 249-272, doi: 10.1098/rspa.2007.0183. [Link]

Emanuel, K. A. and D. S. Nolan, 2004: Tropical cyclone activity and the global climate system. 26th Conference on Hurricanes and Tropical Meteorology, Miami, FL., United States, 240-241.

Fu, B., M. S. Peng, T. Li, and D. E. Stevens, 2012: Developing versus Nondeveloping Disturbances for Tropical Cyclone Formation. Part II: Western North Pacific. Mon. Weather Rev., 140, 1067-1080, doi: 10.1175/2011mwr3618.1. [Link]

Gray, W. M., 1998: The formation of tropical cyclones. Meteorol. Atmos. Phys., 67, 37-69, doi: 10.1007/ BF01277501. [Link]

Harr, P. A. and R. L. Elsberry, 1991: Tropical Cyclone Track Characteristics as a Function of Large-Scale Circulation Anomalies. Mon. Weather Rev., 119, 14481468, doi: 10.1175/1520-0493(1991)119<1448:TCTC AA $>2.0 . C O ; 2$. [Link]

Harr, P. A. and R. L. Elsberry, 1995: Large-Scale 
Circulation Variability over the Tropical Western North Pacific. Part I: Spatial Patterns and Tropical Cyclone Characteristics. Mon. Weather Rev., 123, 12251246, doi: 10.1175/1520-0493(1995)123<1225:LSCVOT>2.0.CO;2. [Link]

Ho, C. H., J. J. Baik, J. H. Kim, D. Y. Gong, and C. H. Sui, 2004: Interdecadal changes in summertime typhoon tracks. J. Climate, 17, 1767-1776, doi: 10.1175/1520-0442(2004)017<1767:ICISTT>2.0. CO;2. [Link]

Hong, C. C., M. Y. Lee, H. H. Hsu, and J. L. Kuo, 2010: Role of submonthly disturbance and 40-50 day ISO on the extreme rainfall event associated with Typhoon Morakot (2009) in Southern Taiwan. Geophys. Res. Lett., 37, L08805, doi: 10.1029/2010GL042761 . [Link]

Julian, P. R. and R. M. Chervin, 1978: A study of the southern oscillation and Walker circulation phenomenon. Mon. Weather Rev., 106, 1433-1451, doi: 10.1175/1520-0493(1978)106<1433:ASOTSO>2.0. $\mathrm{CO} ; 2$. [Link $]$

Kalnay, E., M. Kanamitsu, R. Kistler, W. Collins, D. Deaven, L. Gandin, M. Iredell, S. Saha, G. White, J. Woollen, Y. Zhu, M. Chelliah, W. Ebisuzaki, W. Higgins, J. Janowiak, K. C. Mo, C. Ropelewski, J. Wang, A. Leetmaa, R. Reynolds, R. Jenne, and D. Joseph, 1996: The NCEP/NCAR 40-year Reanalysis Project. Bull. Amer. Meteorol. Soc., 77, 437-472, doi: 10.1175/1520-0477(1996)077<0437:TNYRP>2.0. $\mathrm{CO} ; 2 .[$ Link]

Kim, J. H., C. H. Ho, C. H. Sui, and S. K. Park, 2005: Dipole structure of interannual variations in summertime tropical cyclone activity over East Asia. J. Climate, 18, 5344-5356, doi: 10.1175/JCLI3601.1. [Link]

Kim, J. H., C. H. Ho, H. S. Kim, C. H. Sui, and S. K. Park, 2008: Systematic Variation of Summertime Tropical Cyclone Activity in the Western North Pacific in Relation to the Madden-Julian Oscillation. J. Climate, 21, 1171-1191, doi: 10.1175/2007JCLI1493.1. [Link]

Lee, C. S., 1989: Observational Analysis of Tropical Cyclogenesis in the Western North Pacific. Part I: Structural Evolution of Cloud Clusters. J. Atmos. Sci., 46, 25802598, doi: 10.1175/1520-0469(1989)046<2580:OAO TCI>2.0.CO;2. [Link]

Lee, C. S., L. R. Huang, L. F. Hsiao, D. Y. C. Chen, and L. Y. Chang, 2012: A Study on the Typhoon Precipitation Forecast in Taiwan. 30th Conference on Hurricanes and Tropical Meteorology, American Meteorological Society.

Liu, K. S. and J. C. L. Chan, 2008: Interdecadal variability of western North Pacific tropical cyclone tracks. J. Climate, 21, 4464-4476, doi: 10.1175/2008JCLI2207.1. [Link]

Liu, K. S. and J. C. L. Chan, 2013: Inactive period of western North Pacific tropical cyclone activity in 1998-
2011. J. Climate, 26, 2614-2630, doi: 10.1175/JCLID-12-00053.1. [Link]

Morlet, J., 1983: Sampling theory and wave propagation. In: Chen, C. H. (Ed.), Issues in Acoustic Signal - Image Processing and Recognition, NATO ASI Series (Series F: Computer and System Sciences), Vol. 1, Springer, Berlin, Heidelberg, 233-261, doi: 10.1007/978-3-64282002-1_12. [Link]

Olhede, S. C. and A. T. Walden, 2002: Generalized Morse wavelets. IEEE Trans. Signal Process., 50, 2661-2670, doi: 10.1109/TSP.2002.804066. [Link]

Teng, H.-F., 2016: Formation and Development of Tropical Cloud Cluster in the Western North Pacific. Ph.D. Thesis, National Taiwan University, Taipei City, Taiwan, 178 pp, doi: 10.6342/NTU201602202. [Link]

Teng, H.-F., C.-S. Lee, and H.-H. Hsu, 2014: Influence of ENSO on formation of tropical cloud clusters and their development into tropical cyclones in the western North Pacific. Geophys. Res. Lett., 41, 9120-9126, doi: 10.1002/2014g1061823. [Link]

Torrence, C. and G. P. Compo, 1998: A Practical Guide to Wavelet Analysis. Bull. Amer. Meteorol. Soc., 79, 6178, doi: 10.1175/1520-0477(1998)079<0061:APGTW $\mathrm{A}>2.0 . \mathrm{CO} ; 2$. [Link]

Trenberth, K. E., 1997: The definition of El Niño. Bull. Amer. Meteorol. Soc., 78, 2771-2778, doi: 10.1175/1520-0477(1997)078<2771:TDOENO>2.0 $\mathrm{CO} ; 2$. [Link]

Tu, J.-Y., C. Chou, and P.-S. Chu, 2009: The abrupt shift of typhoon activity in the vicinity of Taiwan and its association with western North Pacific-East Asian climate change. J. Climate, 22, 3617-3628, doi: 10.1175/2009JCLI2411.1. [Link]

Velden, C., B. Harper, F. Wells, J. L. Beven, R. Zehr, T. Olander, M. Mayfield, C. Guard, M. Lander, R. Edson, L. Avila, A. Burton, M. Turk, A. Kikuchi, A. Christian, P. Caroff, and P. McCrone, 2006: The Dvorak tropical cyclone intensity estimation technique: A satellitebased method that has endured for over 30 years. Bull. Amer. Meteorol. Soc., 87, 1195-1210, doi: 10.1175/ BAMS-87-9-1195. [Link]

Wang, B. and J. C. L. Chan, 2002: How strong ENSO events affect tropical storm activity over the western North Pacific. J. Climate, 15, 1643-1658, doi: 10.1175/1520-0442(2002)015<1643:HSEEAT>2.0. $\mathrm{CO} ; 2 .[$ Link $]$

Wang, C. and L. Wu, 2016: Interannual Shift of the Tropical Upper-Tropospheric Trough and Its Influence on Tropical Cyclone Formation over the Western North Pacific. J. Climate, 29, 4203-4211, doi: 10.1175/JCLID-15-0653.1. [Link]

Wu, L., J. Liang, and C.-C. Wu, 2011: Monsoonal Influence on Typhoon Morakot (2009). Part I: Observational Analysis. J. Atmos. Sci., 68, 2208-2221, doi: 
10.1175/2011JAS3730.1. [Link]

Wu, M. C., W. L. Chang, and W. M. Leung, 2004: Impacts of El Niño-Southern Oscillation events on tropical cyclone landfalling activity in the western North Pacific. J. Climate, 17, 1419-1428, doi: 10.1175/1520-0442(2004)017<1419:IOENOE>2.0. $\mathrm{CO} ; 2 .[\underline{\mathrm{Link}}]$

Yu, J. Y., Y.Zou, S. T. Kim, and T. Lee, 2012: The changing impact of El Niño on US winter temperatures. Geophys. Res. Lett., 39, L15702, doi: 10.1029/2012GL052483. [Link]

Zhao, H. and C. Wang, 2016: Interdecadal modulation on the relationship between ENSO and typhoon activity during the late season in the western North Pacific. Climate Dyn., 47, 315-328, doi: 10.1007/s00382-0152837-1. [Link] 